\title{
Older people and local public transit: Mobility effects of accessibility improvements in Sweden
}

\author{
Anders Wretstrand \\ Lund University, Sweden ${ }^{\text {a }}$
}

Sofi Fristedt

Jönköping University, Sweden ${ }^{c}$

\author{
Helena Svensson \\ Lund University, Sweden ${ }^{b}$
}

Torbjörn Falkmer

Curtin University of Technology, Australia;

Jönköping University, Sweden;

Linköping University, Sweden ${ }^{d}$

\begin{abstract}
Several transportation factors concerning older and disabled people are under transition in Sweden at present. By the year 2010, the public transit system must be fully accessible for all passengers. The present survey studied older people, in order to assess the perceived travel opportunities. Questionnaires were sent to a sample of older citizens $(75+)$ in three Swedish mid-sized municipalities. The general conclusions were that even though older people show appreciation of the existing travel opportunities, there was evidence for restricted mobility for some sub-groups of these older people, due to various perceived barriers. These groups have few optional modes, and despite various accessibility measures, special transportation services-the mandatory demand-responsive transport service-continues to provide crucial mobility. Hence, there is more to be done regarding accessibility and usability in public transit for older people. Further studies have to clarify reasons for bus travel cessation. Even larger efforts have to be put into accessibility improvements, in particular intermediate transit solutions in order to meet the regulations and policies.
\end{abstract}

Keywords: Local public transit, Older people, Preferences, Special transportation services

\section{Introduction}

\subsection{The aging society}

Over the next three decades, the number of older people is expected to increase substantially in almost all countries of Western Europe, North America, and Australia (OECD 2001). As people age, an active lifestyle and participation in society are important to maintain quality of life and good health (WHO 2002a). In order to achieve or maintain an active lifestyle, mobility and accessibility will play a major role. Almost all older men and a majority of older women will be car drivers, accustomed to the convenience and flexibility that driving provides (OECD

\footnotetext{
a anders.wretstrand@tft.lth.se

${ }^{b}$ helena.svensson@tft.lth.se

${ }^{c}$ sofi-fristedt@hhj.hj.se

$d_{\text {t.falkmer@curtin.edu.au }}$
} 
2001). Regardless of cultural and policy differences, older people will more commonly be licensed to drive and will travel more by car compared to older people just a decade ago. Furthermore, they will also be less likely to use public transit (Rosenbloom 2001). However, as people grow older, they inevitably tend to change their driving habits, i.e. older drivers reduce nighttime driving, shorten trips, seek parking spaces that are easy to get in and out of, and look for less congested and lower speed roadways and eventually stop driving (Breker et al. 2003; Hakamies-Blomqvist 1996; Rosenbloom 2001; Sirén et al. 2001). Hence, municipalities and regions providing public transit suitable for older people to ease the transition from driving to non-driving will be vital, since public transit supports mobility and an active lifestyle (HunterZaworski 2007; Svensson 2003).

\subsection{Mobility and accessibility}

Mobility has several definitions, ranging from "moving by changing position or location or by transferring from one place to another" (WHO 2002b), to a more holistic view, "also taking movement and degree of independence during such a movement in consideration" (Peel et al. 2005). Social relationships and activities are important elements in the quality of life of older people. With increasing age, these elements are, for various reasons, more difficult to maintain. Therefore, mobility becomes fundamental for older people's participation in social relations and activities (Mollenkopf et al. 1997). Outdoor mobility is often referred to as the ability to move about-either ambulant, using an assistive device, or by means of transportation-sufficiently to carry out activities outside the home. Such outdoor mobility could be seen as a prerequisite not only for obtaining essential commodities and consumer goods, but also for general societal participation (Mollenkopf et al. 2005).

The concept of accessibility includes many dimensions and perspective. Some definitions used in the environmental, planning, and architecture discourse refer to whether and how activities in society can be reached, the possibility of taking part in something desirable, and the geographic proximity in terms of distances and time (Iwarsson and Ståhl 2003). However, accessibility is also a relative concept, implying that it should be expressed as a person-environment relationship. In other words, "accessibility is the encounter between the person's or the group's functional capacity and the design and demands of the physical environment," and as such, it "refers to compliance with official norms and standards" (Iwarsson and Ståhl 2003, 61).

\subsection{The situation in Sweden}

Historically, the urban PT solutions of choice in Sweden have been mainstream bus transit and Special Transportation Services (STS - a demand-responsive, eligibility restricted doorto-door solution for those with severe functional limitations and who therefore cannot use ordinary buses). Municipalities were, and still are, required to provide STS services ${ }^{1}$. In order to meet accessibility requirements-mainstream in the late 1980s was still high-floor buses-the development of the so-called Service Route Traffic (featuring open access, friendly drivers, smaller buses that were easier to access, and area-covering networks with shorter distances between bus

\footnotetext{
${ }^{1}$ Each municipality sets its own STS regulations. Trips must be pre-booked approximately two hours in advance. The fare often corresponds to the regular PT fare. Some municipalities do not have restricted use, but it is commonly provided subject to monthly limits (e.g. 30 trips).
} 
stops) was particularly appreciated by older people because it maintained and enhanced their mobility.

At present, several transportation factors affecting older people are in transition. For example, PT is being made increasingly accessible with a large share of low-floor city buses (up to $100 \%$ in many municipalities). Intermediate solutions in addition to Service Route Traffic, such as Flex Route Traffic ${ }^{2}$ have highlighted the importance of tailor-made transit modes for passengers with special needs, e.g. locomotor impairments (Carlsson 2002; Carlsson et al. 2006; Svensson 2003). STS have also undergone some transition due to increased costs, and eligibility is being increasingly restricted. Policies governing the ownership and use of cars and driver licensing are changing, and the issue of subsidized car purchase for certain groups was recently investigated by the government.

The disability and participation discourse has also shifted. Seven years ago, the Swedish Government Bill "From patient to citizen: a national action plan for disability policy" was passed (Swedish Gov. Bill 1999/2000:79 2000). This Bill represented a step of fundamental importance for directing and funding accessibility investments, requiring that work should be guided by the aim of making public transport fully accessible to older and disabled people by the year 2010. With this aim, planning procedures should be implemented to cover all types of traffic, offering a wide range of services. The question still remains: will these legal objectives ever be met? If the aims of the bill had been restricted to accessibility (defined as an objective design concept), it would perhaps have been possible. However, the aims in the bill were set even higher. According to the contents, the concept of "Design for all" ${ }^{3}$ should also be part and parcel of the implementation. The bill also references "Usability" and "Universal design." Inevitably, this will make the status evaluation by the year 2010 quite difficult. Usability is not only based on compliance with official norms and standards, but takes "into account user evaluations and subjective expressions of the degree of usability." Usability is a measure of effectiveness, efficiency, and satisfaction. Most importantly, there is a "component distinguishing usability from accessibility, viz. the activity component" (Iwarsson and Ståhl 2003, p. 62). The "activity component" refers to activities to be performed by the targeted individual or group in the given environment. The introduction of this third component by the Government Bill will require evaluations of "policy into practice" to include complex investigations of the environmental status, requiring both objective measurements and subjective user evaluations. For example, one question is whether the mobility provisions will not only be accessible, but also usable, i.e. being possible to use and used by the targeted groups, since usability implies that a person should be able to actually use the environment or the transport system, and do so on equal terms.

${ }^{2}$ The FlexRoutes are demand-responsive open-access systems with small, accessible buses. The trips have to be pre-booked, and instead of bus stops, a large number of "meeting points" are offered in order to reduce walking distances to less than $100 \mathrm{~m}$.

${ }^{3}$ Intervention in environments, products and services with the aim that everybody-including future generations, and without regard to age, capabilities or cultural origin-can enjoy participating in society (European Institute for Design and Disability).

${ }^{4}$ The design of products and environments to be usable by all people, to the greatest extent possible, without the need for adaptation or specialized design (Center for Universal Design 1997). 


\subsection{Objectives and scope}

In order to assess the current Swedish situation, the all-encompassing objective of the present study was to analyze the preferred and actual travel opportunities for older people, using a multi-methods approach. Through traveler self-reports, through municipalities and transit authorities' transportation statistics, and through an objective analysis (GIS) of public transportation accessibility, the present paper describes some extracts of the study: provision, supply and use of PT and STS, user satisfaction, and flaws built into the system and factors for non-use.

The scope of the study included older people, aged $75+$, living in three Swedish municipalities with well-recognized PT standards, and with housing only in communities with more than 2,000 inhabitants, in order to secure the existence of a basic PT provision. Focus was set on use of local PT and STS. Car usage was only treated as a background variable.

The next sections of the paper will start with a descriptions of the methods applied, followed by some important results and finally a discussion of these results.

\section{Materials and methods}

\subsection{Study district}

Three municipalities were selected; Helsingborg (population 123,000, area $347 \mathrm{~km}^{2}$ ), Borås (pop. 100,000, $915 \mathrm{~km}^{2}$ ), and Karlskrona (pop. 62,000, 1,043 $\mathrm{km}^{2}$ ). Rural areas were excluded, since these areas have little or no PT supply, and the focus was limited to local PT and STS accessibility. Apart from the towns themselves, only villages with more than 2,000 inhabitants within the municipal border and with existing PT service of any type were selected (see Table 1). All PT vehicles operating within these three municipalities were low-floor or lowentrance buses with designated wheelchair spaces. The full-coverage STS systems were open to wheelchair users, as well as to ambulant passengers.

Helsingborg Service Route Traffic specially designed for mobility-impaired users and offering a high degree of service (Svensson 2003) had been in use for more than a decade in Helsingborg. Organizational measures towards a more efficient PT and STS had been taken, primarily by allocating all resources spent on personal transportation (school buses, special transport services, hospital transport and mainstream services) into one municipal department. This step had resulted in better supervision and had allowed for cost-efficient planning. Furthermore, the municipalities have worked in a target-oriented fashion to make step-by-step improvements in accessibility to built and transit environments. Each year, resources for reducing barriers in the outdoor environment are increasing, and the municipality was awarded the national prize "Accessible Trip 2007" by the Swedish Association of Local Authorities and Regions.

Borås Many of the measures to improve accessibility in Sweden have their origins in the town of Borås. The concept of Service Route Traffic was in essence invented here. Measures regarding barrier-free pedestrian zones and tactile surfaces have been present in the town center for more than 20 years. Targeted actions to increase safety and mobility in town areas with large populations of older people have been implemented and evaluated (Ståhl et al. 1996). Also, the STS system has traditionally been governed by a very generous eligibility system offering low fares and unrestricted use. 
Karlskrona Finally, the hallmark of Karlskrona is the systematic work done by the units of the governing council charged with serving the municipality's disabled and elderly populations. Each plan has to pass through the hands of the disability unit, allowing for analysis and the suggestion of improvements based on a user's (aging and disability) perspective. Furthermore, the STS system has been integrated into the county's center for all demand responsive traffic (Sundström 2006), with the goal of providing more uniform and efficient transport service for older and disabled passengers and for passengers in remote rural areas of the county.

\subsection{Target population}

This study targeted older people, aged 75 or older. The minimum participant age was set at 75 for two reasons: firstly, a similar recent study had also chosen this limit (Carlsson et al. 2006); secondly, a substantial body of knowledge about the travel habits of people 65 years and older already exists. A number of studies, for example Rosenbloom (2001) and Alsnih and Hensher (2003), have shown that people between the ages of 65 and 75 make most of their trips with private cars. Except for a few work-related trips within this group, travel patterns among these "younger older" travelers are similar to those of middle-aged people. Rather than focusing on these patterns the present study selected people who can be expected to be dependent on STS, PT, or transportation support from friends and relatives.

\subsection{Questionnaire}

The questionnaire contained questions about the respondent, his or her physical status, travel habits, traveling obstacles, travel opportunities, and overall satisfaction with existing travel possibilities. The questions focused on STS and PT alternatives. In each municipality, postal questionnaires were sent out to 700 residents over the age of 75 , both in the town center and in small villages outside the main town. The proportional, random sample selection was made from the demographic databases in each municipality (see Table 1).

The questionnaires were to be sent back postage-free within fourteen days. The overall response rate was 46 percent. Since it was considered unethical to bother this elderly target population once more, no reminders were sent out. However, some information about the drop-outs can be mentioned. For example, the mean age was somewhat higher for the drop-out group than for the respondents. The proportion of people living in care homes was also higher among the drop-outs. Some people returned the questionnaire stating (or called to inform the researchers) that the addressee was unable to travel at all or unable to complete the survey instrument. This probably indicates that mobility within the drop-out group was generally lower than among respondents.

The background data on age and sex are described in Table 2. Women represented a majority of the sample and the proportion of persons between 75 and 84 years of age was considerably larger than the proportion of people 85 and over. Just over half of the group lived in one-person households, but large differences existed between men and women in that respect. While 68 percent of the women lived in one-person households, only 39 percent of the men did so. In the villages, the proportion of men living alone was slightly higher (42\%). Compared with the entire Swedish population (Table 2, fifth column), the group aged 75-79 was slightly overrepresented in the sample. 


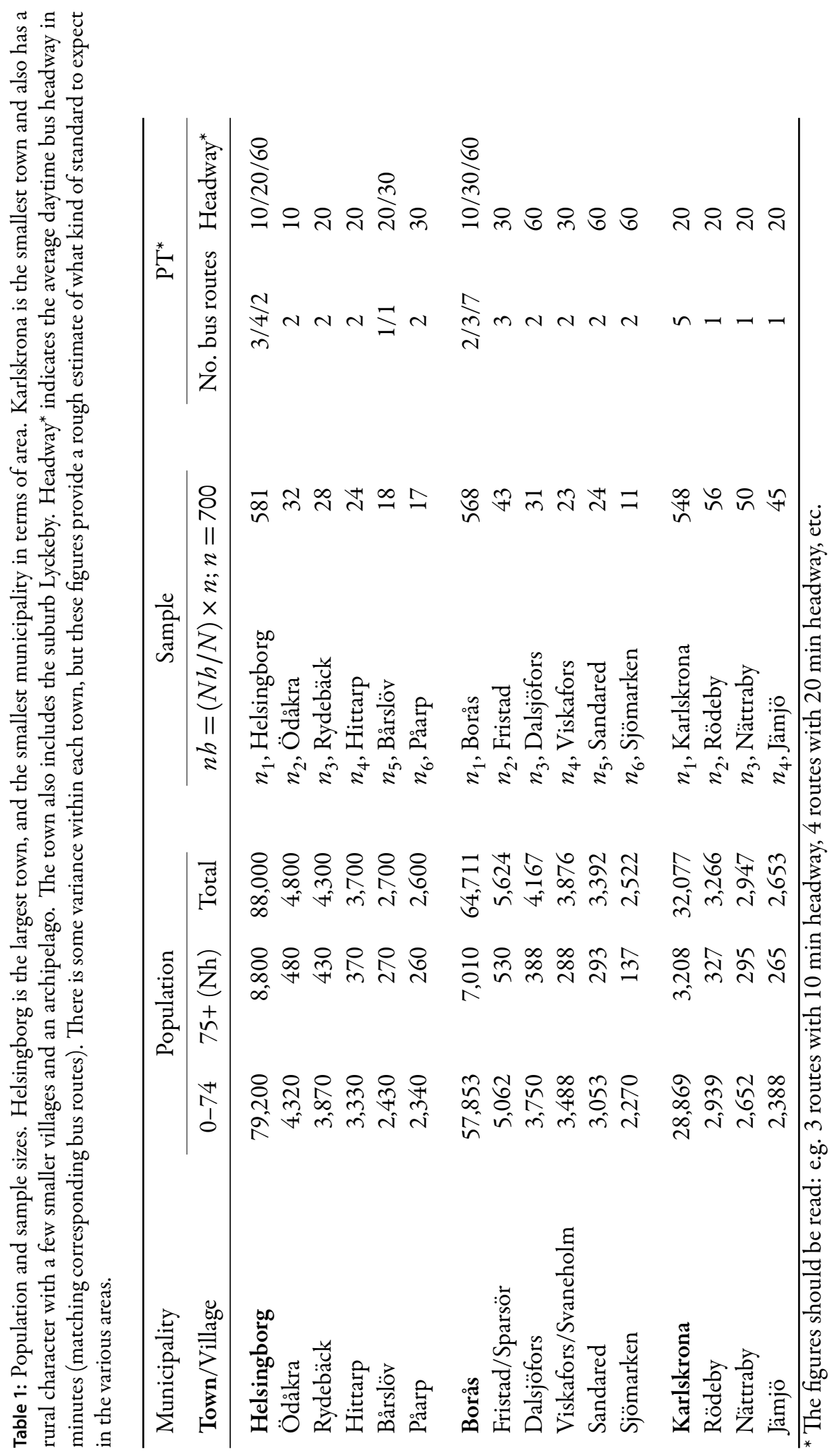


Table 2: Age distribution. Each column sums to 100 percent. In total, 67 percent were female and 33 percent were male. Among respondents aged 90+, 77 percent were female.

\begin{tabular}{lcccc}
\hline \multirow{2}{*}{ Age group } & \multicolumn{3}{c}{ Sample, response rate } & \multirow{2}{*}{$\begin{array}{c}\text { Population } \\
\text { Sweden (total) }\end{array}$} \\
\cline { 2 - 4 } & Karlskrona & Borås & Helsingborg & Sweden \\
\hline $75-79$ & $42 \%$ & $40 \%$ & $42 \%$ & $39 \%$ \\
$80-84$ & $36 \%$ & $34 \%$ & $34 \%$ & $33 \%$ \\
$85-89$ & $15 \%$ & $18 \%$ & $18 \%$ & $19 \%$ \\
$90+$ & $7 \%$ & $8 \%$ & $6 \%$ & $9 \%$ \\
\hline Total & $100 \%$ & $100 \%$ & $100 \%$ & $100 \%$ \\
\hline
\end{tabular}

\subsection{Analyses}

The data were analyzed using non-parametric methods, logistic regression, and log-linear analyses. The output from these non-parametric analyses were based on presented chi-square values $\left(\chi^{2}\right)$ and the related degrees-of-freedom, e.g. $\chi^{2}(4)$. One-way ANOVA was, however, used for GIS (Geographic Information Systems) data comparisons between the municipalities. In the Results section, the respondents were frequently split into "younger" (75-84) and "older" $(85+)$ age groups.

\section{Results}

\subsection{Overview}

\section{General physical ability}

The majority stated that they walked outdoors every day, but approximately 12 percent only walked a couple of times per month or less. Younger respondents were more frequent walkers $\left(\chi^{2}(4)=64.8, p<0.001\right)$. The explanatory factor was the physical status of the person $\left(\chi^{2}(4)=165.0, p<0.001\right)$. Roughly 50 percent reported no physical inconveniences that made it difficult for them to travel. For the rest, however, the physical inconveniences affected, to a greater or lesser degree, their perceived mobility and possibilities for travel. About 46 percent reported locomotor impairments, and 29 percent reported visual and 40 percent hearing impairments. Fully 30 percent used some kind of walking aid, e.g. sticks, crutches, or walkers. In fact, while 56 percent reported that they were able to walk $300 \mathrm{~m}$ or more without taking a break, 12 percent were not even capable of walking $50 \mathrm{~m}$; this was particularly true of respondents over 85 years of age $\left(\chi^{2}(3)=53.8, p<0.001\right)$. About 60 percent reported difficulties with stairs. Men reported fewer physical inconveniences than the women $(F(1,685)=13.43$, $p<0.001)$.

\section{General satisfaction}

When analyzing whether or not the respondents were "satisfied with their overall travel possibilities at hand," the majority (ranging from 77-84 percent in the municipalities) were "rather" or "very satisfied." Although only a quarter of the respondents answered that they were "very satisfied," large proportions were "rather satisfied." Only minor groups were "not satisfied." No 
age effects were registered, but men were more satisfied than women $\left(\chi^{2}(1)=7.14, p<0.05\right)$, and car drivers more satisfied than non-drivers $\left(\chi^{2}(1)=7.40, p<0.01\right)$. Respondents living in city districts, which have larger operating networks, logically scored somewhat higher $\left(\chi^{2}(1)=3.85, p<0.05\right)$. Another significant difference was found between persons entitled to use STS and those not entitled $\left(\chi^{2}(1)=9.22, p<0.005\right)$. For the sample as a whole, some 20 percent reported insufficient travel opportunities, whereas 26 percent of those entitled to use STS were dissatisfied.

Further three-way log-linear analyses of the question "Do you wish to travel more?" produced a final model, in which the second order interaction (AGE $\times$ TRAVEL_MORE) was significant, $\chi^{2}(1)=12.8, p<0.001$. To further break down this effect, separate chi-square tests revealed $\chi^{2}(1)=13.77, p<0.001$ in the cities, yet insignificant results $\left(\chi^{2}(1)=0.38\right)$ in the villages. Odds ratios indicated that older people $(85+)$ in cities were two times more likely to want to travel more (1.3 times more likely in the villages).

Declining health and an overly complex transit system were identified as the main factors for not traveling as much as wanted, whereas the factor "lack of travel opportunities" was labeled less important. Actually, almost one-fifth stated that they refrained from making certain trips. Trips to visit friends and relatives were most commonly omitted, whereas necessary trips to service providers and hospitals were seldom excluded. Odds ratios indicated that people reporting at least one of the physical limitations considered influential as a mobility constraint were almost five times more likely to express a desire for increased travel than those who did not report any significant physical limitations.

\subsection{Car use}

Overall, 61 percent reported having a valid driving license. Men were more likely to be licensed than women $\left(\chi^{2}(1)=114.8, p<0.001\right)$, and respondents under 85 were more likely to be licensed than those over $85\left(\chi^{2}(1)=45.4, p<0.001\right)$. Hence, there were large groups that both had a car in the household and also drove themselves. About 40 percent of the younger respondents and 15 percent of those over 85 both had a car and drove it, compared to the 45 percent in the villages and 53 percent in the cities who did not have a car in the household. There were also large differences between men and women. Odds ratios indicated that men in the cities were 8.1 times more likely to have a car and drive it (9.6 times more likely in the villages). Following these facts, the majority of the women were dependent on taxi, PT or by the assistance of someone outside their own household for mobility purposes.

\subsection{STS: Demand-responsive services}

\section{Group patterns}

In total, one-quarter of the respondents were eligible to use STS. Eligibility was generally more common among women, primarily among the over-85 group $\left(\chi^{2}(1)=21.7, p<0.001\right)$. The proportion among women was approximately double the proportion among men. This fact was partly explained by mean age differences between the sexes. It should be noted that almost one-fifth of the respondents not eligible to use STS assessed themselves as being in a condition that should allow for STS eligibility, with a slight emphasis on both younger $\left(75-84, \chi^{2}(1)=\right.$ $3.4, p<0.05)$ and older women $\left(\chi^{2}(1)=3.3, p<0.05\right)$. 
Among respondents not eligible to use STS, 31 percent did not have a car in the household. These people were dependent on taxis, buses, other regular PT services, or private cars driven by someone outside the household. The results showed that within this group, 39 percent traveled by bus at least twice a week. However, 32 percent seldom or never traveled by bus.

In order to describe the group of STS-eligible respondents, a logistic regression analysis was performed. The results are presented in Table 3. Factors that predicted potential STS usage included age (odds ratios indicated that younger people, aged 75-84, were 4.3 times less likely to be STS users), self-reported locomotor impairment (7.2 times more likely) and reduced walking capacity (7.9 times more likely).

Table 3: STS characteristics, prediction: If a person is unable to walk $300 \mathrm{~m}$, older than 85 years and states one or more mobility impairment, the model predicts $83 \%$ of all STS cases. $R^{2}=0.33$ (Cox \& Snell), 0.50 (Nagelkerke).

\begin{tabular}{lcccc}
\hline Included, model & \multicolumn{3}{c}{$95 \%$ CI for $\exp (b)$} \\
\cline { 3 - 5 } & $\mathrm{B}(\mathrm{SE})$ & lower & $\exp (b)$ & upper \\
\hline Constant & $-0.887^{*}(0.277)$ & & & \\
Age & $-1.459^{*}(0.220)$ & 0.151 & 0.233 & 0.358 \\
Locomotor impairment & $-1.983^{* *}(0.300)$ & 0.076 & 0.138 & 0.248 \\
Reduced walking capacity & $2.061^{* *}(0.261)$ & 4.693 & 7.852 & 13.139 \\
\hline
\end{tabular}

${ }^{*} p<0.01,{ }^{* *} p<0.001$

\section{STS travel satisfaction}

STS users did not travel particularly frequently. Barely 18 percent traveled more than once a week. People aged $85+$ traveled even less, $\left(\chi^{2}(4)=12.08, p<0.05\right)$. The distribution among respondents eligible to use STS was similar in all three municipalities. However, according to the Public Transit Authority (PTA) ${ }^{5}$ statistics, each person in all age groups made on average 50 trips per year in Borås and Helsingborg, but only 27 in Karlskrona. This did not have any effects within the studied sample, and all three municipalities showed a similar response pattern regarding STS travel quality. In fact, 26 percent of the STS sample reported difficulties using STS, compared to the 24 percent that reported difficulties using local buses. As many as 57 percent of the STS respondents reported difficulties when using local buses.

A large majority, 74 percent, was "rather satisfied" or "very satisfied" with the STS services. In comparison, nationwide surveys on actual STS trip assessment (telephone interviews with registered users the day after they had traveled ${ }^{6}$ point towards even higher ratings: 70 percent "very satisfied" and 20 percent "rather satisfied." Furthermore, some differences were observed between groups with various travel demand. Those who wanted to travel more were also more critical to the service levels $\left(\chi^{2}(3)=10.40, p<0.05\right)$.

Various measures had been made recently by the PTAs in order to reduce STS costs. In Borås, persons eligible to use STS were able to travel at zero fare on local buses; in Karlskrona,

${ }^{5}$ The PTA is responsible for PT within local municipalities, and also within regions.

${ }^{6}$ www.sltf.se 


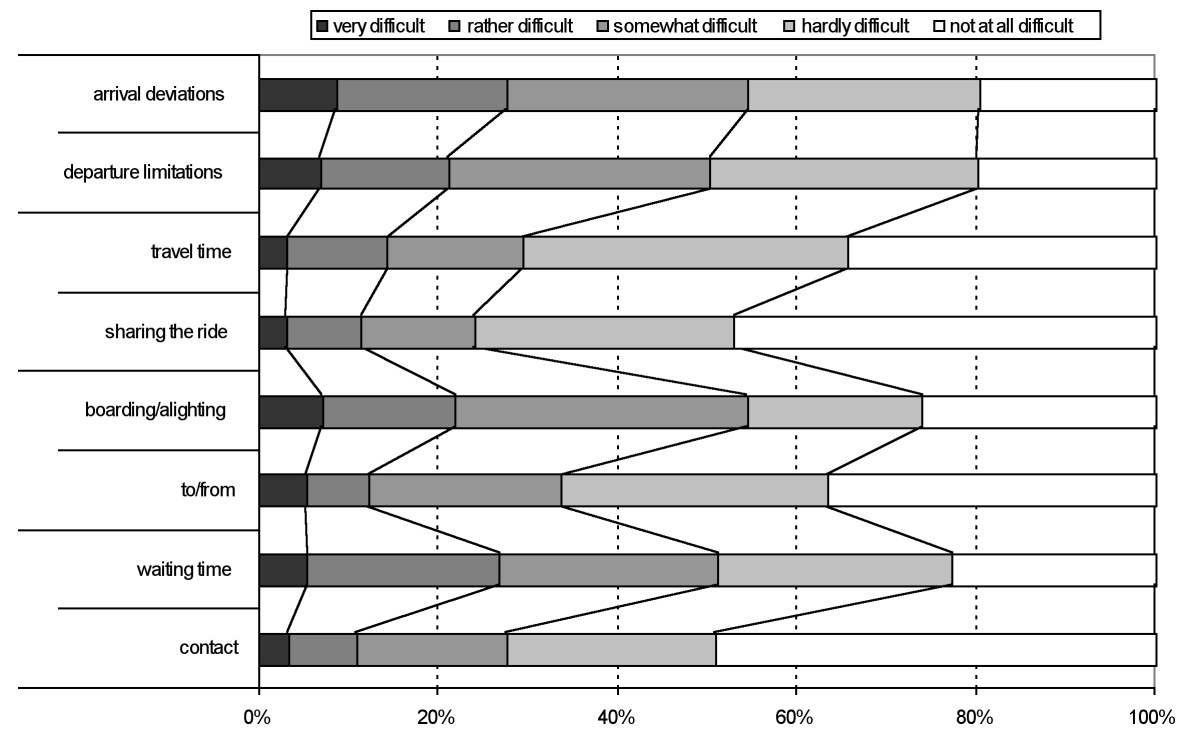

Figure 1: Difficulties experienced while using STS. $n=219$ (Karlskrona 29\%, Borås 37\%, Helsingborg 34\%)

the bus fare reduction was 50 percent. Despite these efforts, no modal shift was observed. On the contrary, STS travel remained unchanged in Karlskrona and even increased in Borås.

\subsection{PT: Traveling by bus}

\section{Group patterns}

Generally, the market share for public transit is quite low. It is, however, expected that the older generations are frequent bus passengers. This was confirmed by the results in the present study. Nonetheless, in the cities more than 27 percent of those questioned-and in the villages more than 50 percent-did not travel by bus at all. Only 16 percent traveled by bus two or more times per week. People in cities traveled more frequently by bus than people in villages $\left(\chi^{2}(1)=60.4, p<0.001\right)$ and women used buses more than men $\left(\chi^{2}(1)=28.4, p<0.001\right)$, but within the group who never traveled by bus, the ratio of men to women was equal.

What was the reason for "bus travel cessation"? Figure 2 shows that most respondents simply answered that they were traveling by car or by STS instead. Scrutinizing such a statement, the underlying reasons suggested that it was too difficult or too laborious to travel by bus; wellknown difficulties with boarding and alighting and long walking distances may be some reasons for modal shift. The reason "boarding/alighting" probably included more than the actual entrance or exit step heights, since only low-floor vehicles were in use. Other common answers were limited services and insecure feelings while traveling alone. The largest difference between men and women in this respect was the proportion that answered that they used their car or STS, respectively. Far more men answered that they traveled by car instead of by bus $\left(\chi^{2}(1)=12.94, p<0.001\right.$, while the women referred to STS as more of a substitute mode of travel $\left(\chi^{2}(1)=15.94, p<0.001\right)$. In total, the respondents that had ceased using the local transit buses experienced them as too difficult to use, regardless of the documented accessibility improvements being made. 


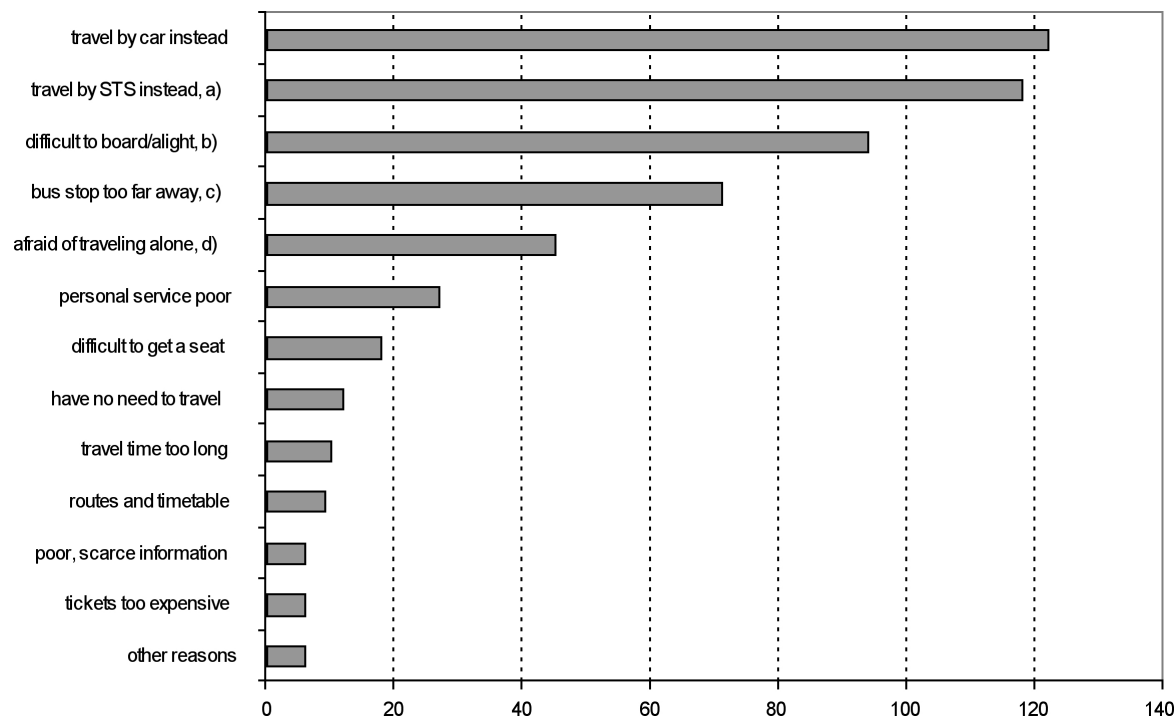

Figure 2: Local "bus travel cessation." Reasons for not using local public transit by bus anymore; each respondent was asked to indicate all relevant reasons, therefore the total sum is more than $100 \%$. a) more common among people over 85 years, $\chi^{2}(1)=19.2, p<0.001$; b) do., $\chi^{2}(1)=14.9, p<0.001$; c) do., $\chi^{2}(1)=8.8, p<0.005$; d) do., $\chi^{2}(1)=4.8, p<0.05$ and among people living in the cities, $\chi^{2}(1)=5.9, p<0.01$.

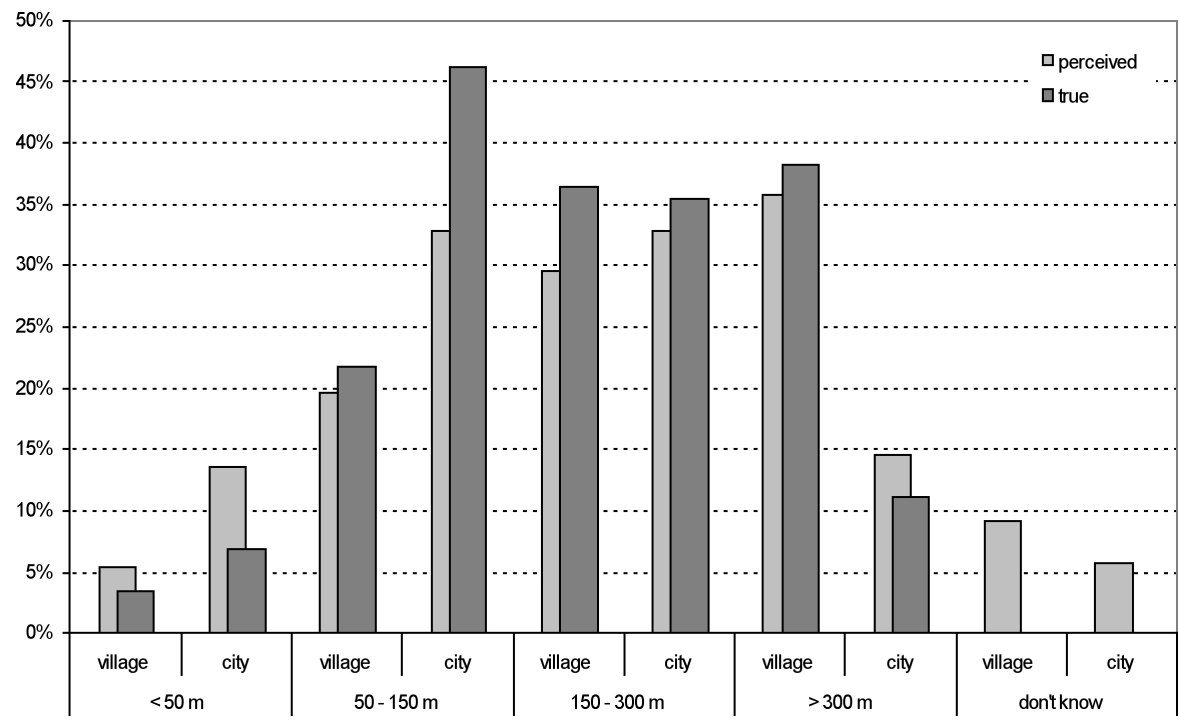

Figure 3: Bus stop distances. "True" distance determined by GIS data, "perceived" distance assessed by respondents (no significant differences, Wilcoxon signed rank test, indicating high validity of the selfreported data). There might, however, be a slight tendency to under-estimate the short distances. 
Table 4: Bus stop distance and PT density. There was a significant effect of municipality (only in town districts), and Borås had closest PT access, $F(2,783)=10.51, p<0.001$. Borås also had the largest bus stop density (mean distance of the four closest bus stops), from the perspective of the respondents. Karlskrona, being the smallest municipality, also had the lowest density in both town and village districts.

\begin{tabular}{llccccc}
\hline \multirow{2}{*}{ Municipality } & & \multicolumn{2}{c}{ Distance, $\mathrm{m}$} & & \multicolumn{2}{c}{ Density, m } \\
\cline { 3 - 4 } \cline { 6 - 7 } & & Mean & Std. & & Mean & Std. \\
\hline \multirow{2}{*}{ Karlskrona } & village & 258 & 197 & & 397 & 158 \\
& town & 203 & 178 & & 269 & 171 \\
\multirow{3}{*}{ Borås } & village & 335 & 552 & & 352 & 131 \\
& town & 150 & 117 & & 199 & 80 \\
\multirow{3}{*}{ Helsingborg } & village & 308 & 206 & & 387 & 197 \\
& town & 175 & 93 & & 238 & 78 \\
\hline
\end{tabular}

According to the GIS data, 25 percent of respondents in villages and 53 percent of respondents in town areas lived less than 150 meters from a bus stop, which could be regarded as fairly high standards. The results also indicated that walking distance affected bus use: distance from dwelling to bus stop had a significant effect on travel frequency, $F(4,929)=3.179, p<0.05$. The closer to a bus stop, the more often PT was used. STS eligibility was not more common among those who had longer distances to walk, rather the opposite was found to be true $(F(1,920)=3.845, p<0.05)$. While comparing walking capacity and distance to the bus stop, it could be concluded that among those who claimed a certain physical disability or the use of walking aids, at least 55 percent (up to a maximum of 80 percent, since distance estimates were grouped into ranges of $<50 \mathrm{~m}, 50-150 \mathrm{~m}, 151-300 \mathrm{~m},>300 \mathrm{~m}$ ) were able to reach their nearest bus stop. Consequently, the remaining group (20-45\%) very seldom, if ever, traveled by bus (better physical ability allowed for more frequent bus use, $\chi^{2}(3)=40.7, p<0.001$ ). Only 62 percent of the respondents with a walking capacity up to $150 \mathrm{~m}$ were entitled to STS, and among the remaining 38 percent, roughly 80 percent had no car in the household.

Further three-way log-linear analyses of the question "how often do you travel by bus" (reduced to a dichotomous variable OFTEN_BUS - often-seldom) produced a final model in which the second order interactions (AGE $\times$ OFTEN_BUS) and (AGE $\times$ DISTRICT_TYPE) were significant: $\chi^{2}(1)=5.23, p<0.05$ and $\chi^{2}(1)=42.37, p<0.001$. To further break down these effects, separate chi-square tests revealed significant differences $\left(\chi^{2}(1)=3.72, p<\right.$ $0.05)$, in the cities but insignificant results $\left(\chi^{2}(1)=1.93\right)$ in the villages. Odds ratios indicated that older people $(85+)$ in the villages were 2.4 times less likely to travel often, whereas they were only 1.3 times less likely to travel often in the cities.

\section{PT travel satisfaction}

As Figure 4 shows, there were large groups that did not experience any difficulties when traveling by bus. Still, there were some groups that did. And as shown before, there were groups 


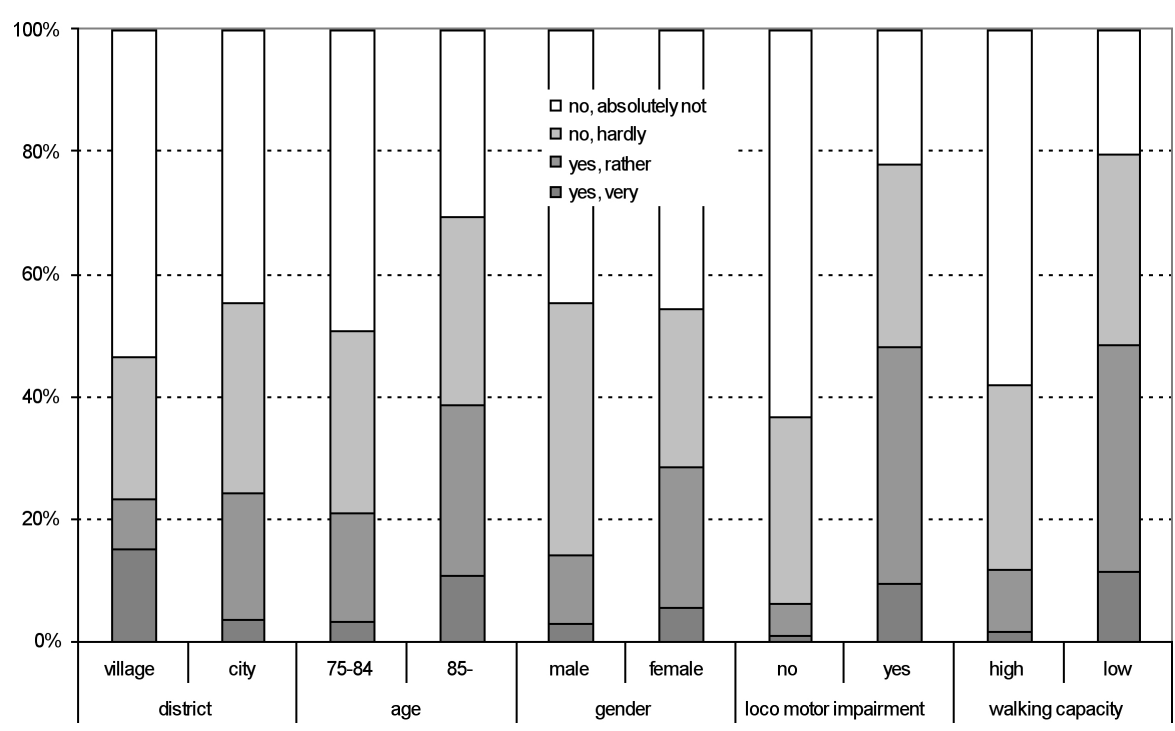

Figure 4: Difficult to use local bus transit. Several significant differences between groups: district $\chi^{2}(3)=21.00$; age $\chi^{2}(3)=21.93$; sex $\chi^{2}(3)=19.50$; mobility impairment $\chi^{2}(3)=146.3$; walking capacity $\chi^{2}(3)=106.4$, all $p<0.001$. Note the asymmetric response scale.

of older people who had ceased traveling by bus. Figure 4 depicts several differences between groups, results that were consistent with what previously has been presented.

Many of the respondents reported that the levels of bus service provision had changed over the last years. Only 11 percent assessed the village PT standard as declining, whereas 54 percent had noticed improvements. In the town districts, only 10 percent reported perceiving a standard decline, whereas 42 percent reported an increase. This indicated that accessibility improvements had not been confined entirely to urbanized areas. For example, the respondents from the municipality of Borås (which had the largest area covered by a PT network) reported less average improvement. Despite these improvements, respondents did not generally travel more by bus than they had a few years ago; only 12 percent in the villages and 22 percent in the town districts had increased their bus travel.

\section{Discussion}

The results demonstrated a typical effect of human physical decline: reduced outdoor mobility. As respondents' the age increased, all modes were less frequently used. However, significant groups within this aging population were still quite physically active as pedestrians, car drivers, and bus passengers.

Large groups were also quite satisfied with the possibilities available to them for local travel, thus maintaining their expected level of mobility. Although the general satisfaction was slightly higher in the cities, a surprisingly large number in the village areas was not particularly dissatisfied, despite the relatively poor PT provision in those areas. This was probably due to the effect of categorization, referring to which level of standard to be expected (Wretstrand 2007). Another aspect of categorization was that particularly older $(85+)$ people in cities would like to travel more than they have done, referring to their own mobility patterns in their more active 
days. The results also underscored gender differences, viz. that women still have less access to private cars, yet evince a higher demand for increased traveling (Rosenbloom 2001; Sirén et al. 2001).

The importance of STS services in Sweden as a key to mobility for locomotor-impaired people has once again been demonstrated. Due to the higher costs per trip in the STS system compared to mainstream solutions, PTAs are striving to transfer passengers from STS to $\mathrm{PT}$ in order to reduce municipal and regional transit costs. It has been estimated that it may be possible to convert up to 90 percent of current STS trips to PT trips. However, this goal may be difficult or impossible to achieve for the population covered by this study. Simply estimating the number of subjects who were able to reach their nearest bus stop reveals that a substantial segment of the study population is unable to use mainstream PT as provided today. Further restricting STS eligibility in order to force a modal shift will only reduce mobility for locomotor-impaired people, regardless of age. Analysis of the data related to STS demonstrated well-known system flaws, and also showed that "younger" respondents (age 75-84), being more frequent travelers, also were more critical of various standard factors typical for production-oriented, demand-responsive transit solutions.

The lower appreciation of STS seen in this research, compared to the nationwide surveys conducted by the PTAs, could be explained by different factors. One important aspect is that the incidence of negative experiences is quite low, so most queries dealing with a particular trip are likely to produce high scores. In our study, we asked for a general assessment of services, allowing respondents to "integrate" all (good and bad) experienced into one evaluation. Critical voices in mass media, particularly from disability organizations, often come from people with disabilities who use STS services to commute to work and for active societal participation. It is generally agreed that these user groups have much higher standards for reliability, dignity, and disability awareness compared with the majority of users (old and very old passengers). The nationwide surveys were initiated, in part, to allow municipalities to address these critiques.

In all municipalities, accessible buses were operating. The results showed that introducing low-floor or low-entrance buses in village and rural areas as well as in urban areas probably has had significant mobility effects. The differences between cities and villages were significant, yet not always as obvious as would have been expected.

One of the most important reasons respondents stopped using PT buses was the boarding/alighting procedure. This indicates that, in order to remove boarding/alighting barriers, low-floor vehicles and adjusted pavements are not sufficient accessibility affordances. Carlsson (2002), for instance, showed several aspects of existing obstacles related to the bus stops: cycleways conflicting with pedestrian environments; narrowness; poor weather protection; many buses at the same time; poor or incorrect information content and design; stress; etc. However, in order to enhance accessibility and keep older passengers within the PT system, further research is needed to identify crucial factors that can be addressed in order to create optimal accessibility and usability.

Regarding methodological aspects, the match between objectively and subjectively assessed bus stop distance confirmed the validity of several previous studies in which assessed distances have been used as indicators and as independent variables. In the present study, bus stop distance as such also emerged as a key factor influencing mobility. This fact has been demonstrated in previous stated preference studies (Svensson 2003) and is now quite logically proved to be correlated with travel frequency. Those living too far from a bus stop (outside walking capacity 
range) consequently refrained from using buses. It should, once again, be underscored that the transit services available in the chosen study districts could be seen as "best practices"; the majority of other municipalities in Sweden provide PT systems that are even less accessible. Hence, the non-riding sub-populations (outside walking capacity range) could be suspected to be even larger on a national level.

The present study has shown that despite an increasing use of private cars, the existence of an STS system for locomotor-impaired people, and a PT transit system with a mean distance to the nearest urban low floor bus stop below $300 \mathrm{~m}$, there are still groups of older people with very limited mobility options. Therefore, in order to meet the governmental objective of a "fully accessible PT system," accessibility measures must recognize the importance of intermediate PT solutions as a means to bridge the gap. These findings also highlight the importance of clearly defining the concepts being discussed in the ongoing accessibility discourse. The studied systems were highly accessible-low-floor vehicles, fairly short walking distances compared to the urban average of $300 \mathrm{~m}$, improved bus stops and pedestrian environments-yet, for significant groups, the systems are not fully usable, with reference to Iwarsson and Ståhl (2003). Thus, meeting the objectives of (Swedish Gov. Bill 1999/2000:79 2000) will be difficult within the two years remaining until 2010, unless even more wide-coverage, open-access intermediate solutions are introduced.

In the future, car use will be increasingly important for older people in order to maintain mobility and participation. This has a number of sustainability implications-the most obvious being increased environmental pollution (Rosenbloom 2001). The current environmental discourse and the effects of global warming will probably result in new and revised pricing policies, imposing substantial limitations on private car use. Therefore, an even greater challenge lies ahead in the domain of PT. The design of PT services must be informed not only by an accessibility perspective, but also by a usability perspective, in order to induce a modal shift from private automobiles to public modes. However, the mainstream solutions will never be able to fully replace individual STS solutions. Instead, intermediate solutions will be required: Service Route Traffic attracting older but experienced bus travelers; Flex Route Traffic attracting STS travelers who are used to the pre-booking procedure; enhanced information and travel training services attracting car users in order to facilitate modal shift.

\section{Conclusion}

Even though older people show appreciation of their existing travel opportunities, restricted mobility prevails for some older groups, due to various perceived barriers. Hence, there is more to be done regarding accessibility and usability in public transit for older people.

Urban and transportation planning procedures will have to address users' needs using a two-pronged approach:

- Accessibility assessment: Measurements in the environment (PT system and infrastructure) could be objectively assessed according to norms and standards, while simultaneously considering the functional capacity of the target groups. Potentially productive areas of investigation include dimensions, slopes, reduction of easily removable obstacles, bus stop proximity, booking center access, and waiting times. As such, accessibility assessment has a character of objective inventory. 
- Usability assessment: The environment (system and infrastructure) could be investigated by applying a user's subjective perspective, through interviews (both quantitative and qualitative) and participant observation. Such methods could provide further insights in order to identify "soft barriers" in the social context or the dynamics and complexity in a large bus terminal. Usability assessment, targeting "perceived accessibility," could provide further feedback in order to assess the mobility effects of accessibility measurements.

In Sweden, at present, the existing accessibility policies reveal real challenges for both municipalities and PTAs. Even larger efforts must be put into accessibility improvements, in particular intermediate transit solutions in order to meet these regulations and policies. The studied group of $75+$ had few optional modes, and despite various accessibility measurements, STS continues to provide crucial mobility.

\section{Acknowledgments}

This paper was prepared within the Center for Ageing and Supportive Environments (CASE), at Lund University, financed by the Swedish Council for Working Life and Social Research. The study as such was financed by the Swedish Governmental Agency for Innovation Systems (VINNOVA).

\section{References}

Alsnih, R. and D. Hensher. 2003. The mobility and accessibility expectations of seniors in an aging population. Transportation Research A, 37(10):903-916.

Breker, S., P. Henrikson, T. Falkmer, E. Bekiaris, M. Panou, G. Eeckhout, et al. 2003. Problems of elderly in relation to the driving task and relevant critical scenarios. Technical Report Deliverable report No. D.1.1, AGILE - AGed people Integration, mobility, safety and quality of Life Enhancement through driving, EU Quality of Life and Management of Living Resources.

Carlsson, G. 2002. Catching the bus in old age: Methodological aspects of accessibility assessments in public transport. Lund, Sweden: Lund University.

Carlsson, G., A. Ståhl, and Y. Westerlund. 2006. Public transportation alternatives to personal vehicles in old age. Paper presented at the International Conference on Aging, Disability and Independence (ICADI), St. Petersburg, Florida, USA.

Center for Universal Design. 1997. Principles of universal design. URL http://www.design. ncsu.edu/cud/about_ud/udprincipleshtmlformat.html.

European Institute for Design and Disability. Definition of “Design for all”. URL http://www. design-for-all.org.

Hakamies-Blomqvist, L. 1996. Research on older drivers: A review. IATSS Research, 20(1):91-101.

Hunter-Zaworski, K. 2007. Getting around in an aging society. Planning, 73(5):22-25.

Iwarsson, S. and A. Ståhl. 2003. Accessibility, usability and universal design; positioning and definition of concepts describing person-environment relationships. Disability and Rehabilitation, 25(2):57-66. 
Mollenkopf, H., F. Marcellini, I. Ruoppila, P. Flaschentrager, C. Gagliardi, and L. Spazzafumo. 1997. Outdoor mobility and social relationships of elderly people. Archives of Gerontology and Geriatrics, 24(3):295-310.

Mollenkopf, H., F. Marcellini, I. Ruoppila, Z. Széman, and M. Tacken. 2005. Enhancing mobility in later life. Amsterdam: IOS Press.

OECD. 2001. Ageing and transport: Mobility needs and safety issues. Paris: Organisation for Economic Co-operation and Development.

Peel, C., P. Baker, D. Roth, C. Brown, E. Bodner, and R. Allman. 2005. Assesing mobility in older adults: The UAB study of aging life-space assessment. Physical Therapy, 85(10):1008-1019.

Rosenbloom, S. 2001. Sustainability and automobility among the elderly: An international assessment. Transportation, 28(4):375-408.

Sirén, A., S. Heikkinen, and L. Hakamies-Blomqvist. 2001. Older female road users: A review. Report 467A, VTI, Linköping.

Ståhl, A., K. Brundell-Freij, O. Grönvall, and M. Magdeburg. 1996. Tillgänglig kollektivtrafik för äldre och funktionshindrade. Betydelse av reskedjans olika delar. [accessible public transport for older and disabled persons. The importance of the travel chain perspective]. Rapport 1996:7, KFB, Stockholm.

Sundström, E. 2006. Utveckling av en integrerad tjänst: En fallstudie inom kollektivtrafikbranschen [Development of an integrated service: A case study in public transit]. Karlstad, Sweden: Service Research Center, Karlstad University.

Svensson, H. 2003. The public transport preferences for elderly people: A study related to individual capacity and environmental stress in service route traffic and other systems. Bulletin 215, Department of Technology and Society, Lund University, Lund, Sweden.

Swedish Gov. Bill 1999/2000:79. 2000. Från patient till medborgare [From patient to citizen - a national action plan for disability policy].

WHO. 2002a. Active ageing: A policy framework. Geneva: World Health Organisation.

WHO. 2002b. ICF-International classification of functioning, disability and health. Geneva: World Health Organisation.

Wretstrand, A. 2007. Comfort and safety as perceived by wheelchair-seated bus passengers. Transportation Planning and Technology, 30(2-3):205-224. 